\title{
Intelligent Tourist Guide System using Web Development
}

\author{
Abrar Islam, S Priya, Aakrshan Sharma
}

\begin{abstract}
There is a huge development in the Information Technology or IT sector recently. Also, there is a massive use of Geographic Information System or in short, we say as GIS nowadays. Tourism Industry is getting more and more advantage specially from GIS. GIS and Tourism Industry are bonding together in a smooth and progressive manner. In order to connect GIS and Tourism, that means in order to establish a bonding between them network is required or we can say connectivity is required. Network allows nodes to share resources in digital telecommunications. So, GIS and Tourism are interconnected with network. Network form infrastructure of modern society. When tourists visit a new place, they might not know about the place in a detailed manner or it might be just a new place for them. Even services like Google which uses the Navigation system and uses the GIS system might not have all details of a place of very low tourist interests. But here we propose Intelligent Tourist Guide System using Web Development which will help tourists travelling to different parts of the world and also local people can advertise their place in order to make it a Tourist Spot and make their area famous.
\end{abstract}

Keywords : GIS, Linear Search, Quicksort, Web Page.

\section{INTRODUCTION}

TOURISM, as we speak of is a growing industry. with increasing importance to countries globally. With the increase in growth of transportation globally which means that people can travel from anywhere to anywhere, people tend to visit places very often. Nowadays everyone has money and also people like to visit new places and upload in their social accounts. But not all places are not meant for every people. The reasons could be weather, diseases, the type of food and hygienic conditions. Also, languages could be problem while visiting other places. Though nowadays due to innovation in computer worlds new apps and devices are created which help in translating the languages and thus making communication easy for the tourist. Also, people nowadays do a research about the place they are about to visit using google and other websites. But google is based on navigation-based system and only shows places which are of

Revised Manuscript Received on December 30, 2019.

* Correspondence Author

Abrar Islam, Student BTECH CSE (3rd year), SRM Institute of technology, Ramapuram abrar3islam@gmail.com

S.Priya, Assistant professor CSE (O.G), SRM Institute of technology, Ramapuram pri1988cse@gmail.com

Aakrshan Sharma, Student BTECH CSE ( $3^{\text {rd }}$ year), SRM Institute of technology, Ramapuram aakrshansharma@gmail.com

(C) The Authors. Published by Blue Eyes Intelligence Engineering and Sciences Publication (BEIESP). This is an open access article under the CC BY-NC-ND license (http://creativecommons.org/licenses/by-nc-nd/4.0/) great tourist interest. It won't show about the place which is not searched but anyone in google. Because google is based on Machine Learning Algorithm and it shows about the most frequent searches. So only the highest searched places will show first in google. Also, they look the feedback about the place like what are the reviews of the place. Mostly travellers who already visited the place reviews the place. In that way they know about the place first-hand. But not always all reviews are genuine and authentic.

These are the problems faced by people before they visit a new place. When they find a place to visit then the review might not be as good to visit. And also, even if the reviews are good then the cost might be a problem. Also, the food might not be good or be a problem. Also, the weather conditions might not be suitable for visit.

Real-world reviews were taken from hotels and restaurants and places of visit, and found that the tourist reviews were based on the mood of the travellers. Suppose the mood of the traveller is good, then he reviews it as good and if the mood is bad then he reviews it as bad. So the reviews of travellers is not that much of help for fellow travellers.

In order to help tourists to get a fair and nice review, we propose the INTELLIGENT TOURIST GUIDE SYSTEM. Here we create a web page and ask the people of the native place to upload details about their place and also upload photos of their places which could become tourist centres. Also, on the other hand the tourist also creates an account in the same webpage under tourists. We use Algorithms to search the best details and photos and make the same available for the tourist page. The Tourist can get the genuine details about the place they are going to visit and make the decision in order to visit the place or not.

\section{RELATED WORK}

In this section we deal with the navigation system, website creation and types of algorithm used.

\section{A. Navigation system}

The navigation system work on GIS based system. GIS as already mentioned before is the geographic information system. GIS is used by maths mostly like Google Map.

GIS is designed to capture, store, manipulate, analyse, manage, and present geographic data. By using GIS, we get the geographical location of the place and thus locate the place. As any localite uploads the details of their place, we get the exact location of the place and thus we can pinpoint the exact location in the map. 


\section{Intelligent Tourist Guide System using Web Development}

\section{B. Algorithms used}

In order to find the most visited place by fellow travellers we use the Linear Search Algorithm. Although there are a lot of algorithms available and can be used but linear search algorithm is the easiest and simplest of all.

Now that we found the most visited place by using Linear Search algorithm, we also find the no of times all the places are visited so that we can sort the most visited place. We find the most visited place by using Quicksort Algorithm. Also, Quicksort is chosen because it has best performance in average case.

\section{PROPOSED FRAMEWORK}

\section{A) Data Collection}

In order to travel a place before, a traveller needs to know about the place before going there and also, they have to make some bookings before they go. All these has to be done online and also the main question arises where would they do it?

In order to solve the problem, we create a website in which we give access to the website to both traveller and the businessmen(localites).

For the localites or businessmen, they have to create account in order to upload their property and the nearest tourist attraction. In order to avoid fraud, we set strict parameters for verification for localites. They have to upload a series of proof out of which Aadhar card, Passport, PANCARD, Driving License are a must. Only after verification with relevant authorities we grant them access to the website. They can upload photos, details of the nearest tourist attraction. The attraction should be within a range of $5 \mathrm{kms}$ only.

For travellers, they also need to create account. They should provide Username, Name and password. Anytime they login after that they should login using Username and password. Once they have account, they can check all the travelling places. They can select Country->City->Place.

We also give the extra feature of providing the geolocation of the place in map.

We also create database for the traveller, which contains all places to visit. They can drag and drop the place they want to visit in their wish list. Then they can see the property details of the businessman or localite who uploaded the details and chose whether to stay or not stay in his/her place. Then they can either make payment online or chose to pay at the location itself. They also need to select the date they are travelling in order to keep reservation.

\section{B) Algorithm}

\section{Linear Search ${ }^{[1]}$}

Linear Search Algorithm is used here to find the highest visited place and also to find the place which has been visited the most. ${ }^{[1]}$

A simple approach is to do linear search, i.e. ${ }^{[1]}$

- $\quad$ Start from the leftmost element of arr[] and one by one compare $\mathrm{x}$ with each element of $\operatorname{arr}[]^{[1]}$
- $\quad$ If $x$ matches with an element, return the index. ${ }^{[1]}$

- If $x$ doesn't match with any of elements, return $-1 .^{[1]}$

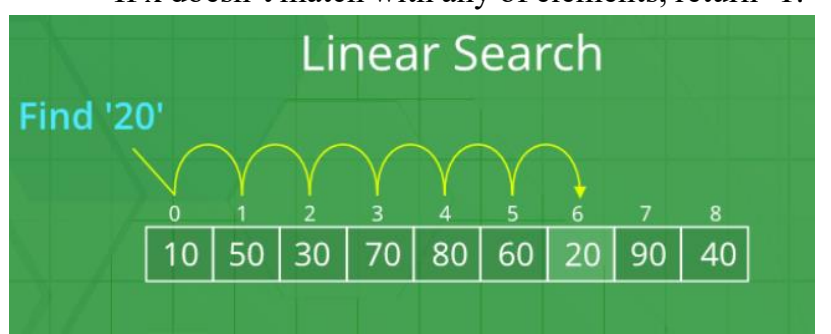

\section{Quicksort ${ }^{[2]}$}

Quick sort works in the following manner: ${ }^{[2]}$

1. Taking the analogical view in perspective, consider a situation where one had to sort the papers bearing the names of the students, by name. One might use the approach as follows: ${ }^{[2]}$

A. Select a splitting value, say L. The splitting value is also known as Pivot. ${ }^{[2]}$

B. Divide the stack of papers into two. A-L and M-Z. It is not necessary that the piles should be equal. ${ }^{[2]}$

C. Repeat the above two steps with the A-L pile, splitting it into its significant two halves. And M-Z pile, split into its halves. The process is repeated until the piles are small enough to be sorted easily. ${ }^{[2]}$

D. Ultimately, the smaller piles can be placed one on top of the other to produce a fully sorted and ordered set of papers. [2]

2. The approach used here is recursion at each split to get to the single-element array. ${ }^{[2]}$

3. At every split, the pile was divided and then the same approach was used for the smaller piles. ${ }^{[2]}$

4. Due to these features, quick sort is also called as partition exchange sort. ${ }^{[2]}$

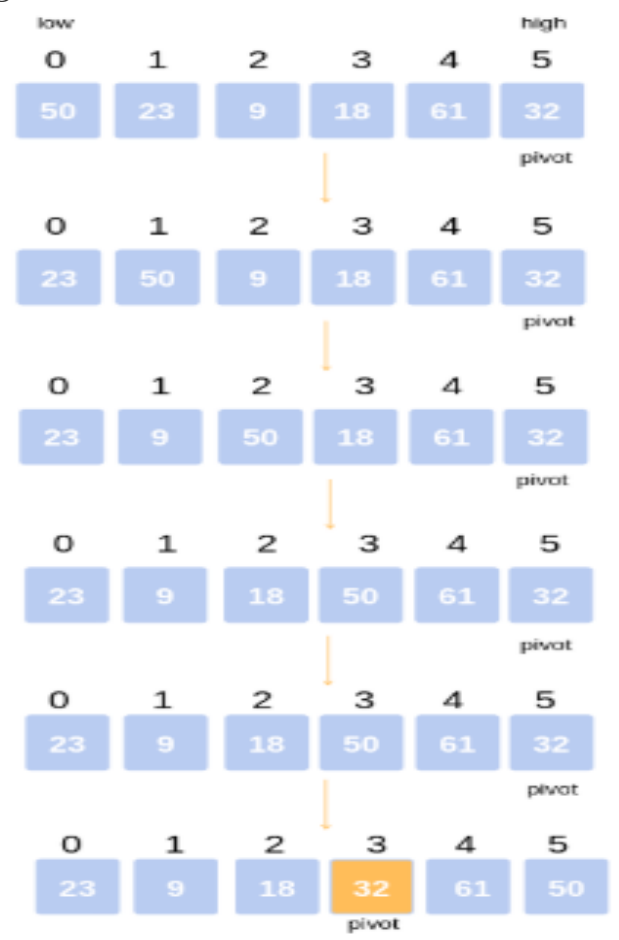

\section{C) Flowchart}

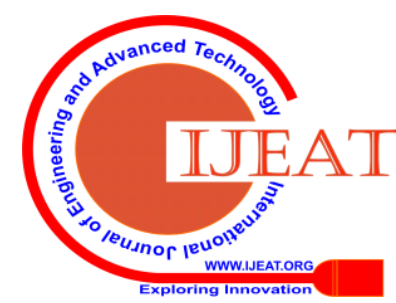




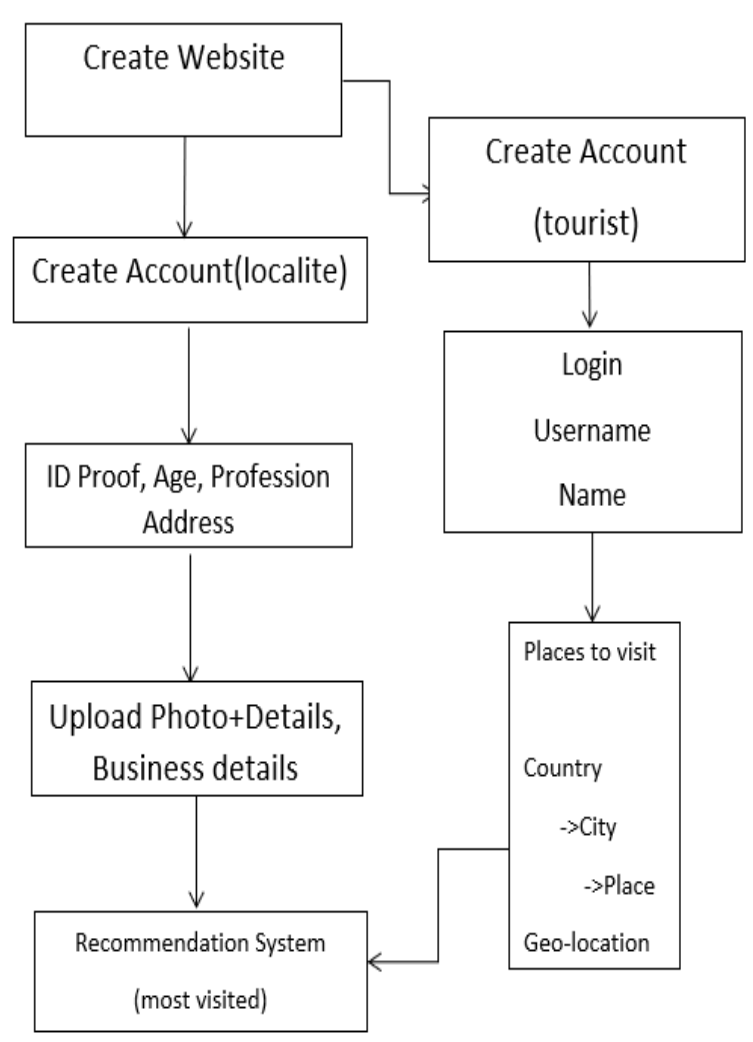

The above flowchart shows the steps for the creation of account for both traveller and localites who are gong to showcase their area.

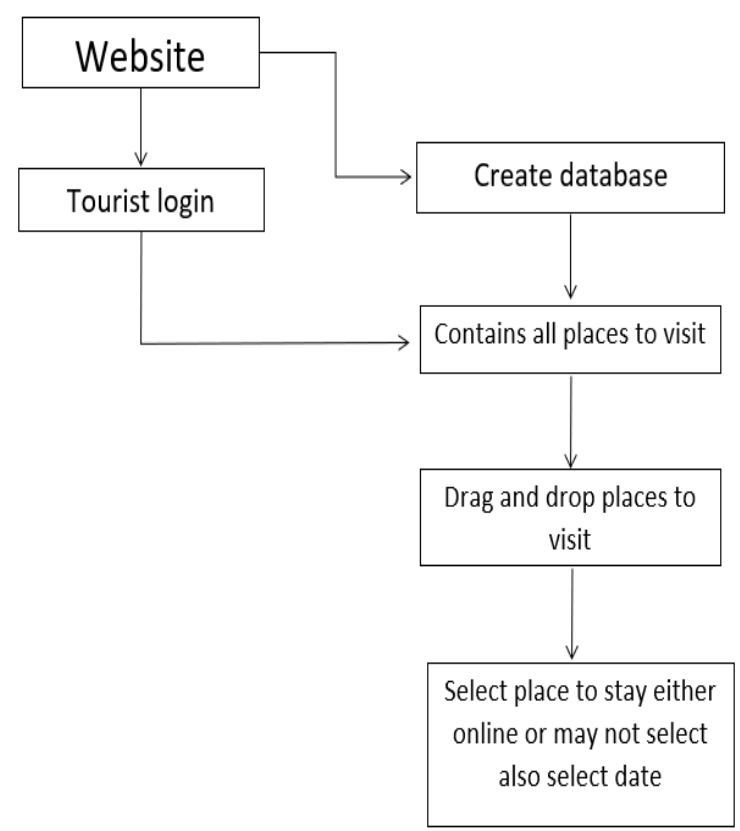

In this flowchart the database which already mentioned earlier is shown and its uses are highlighted here.

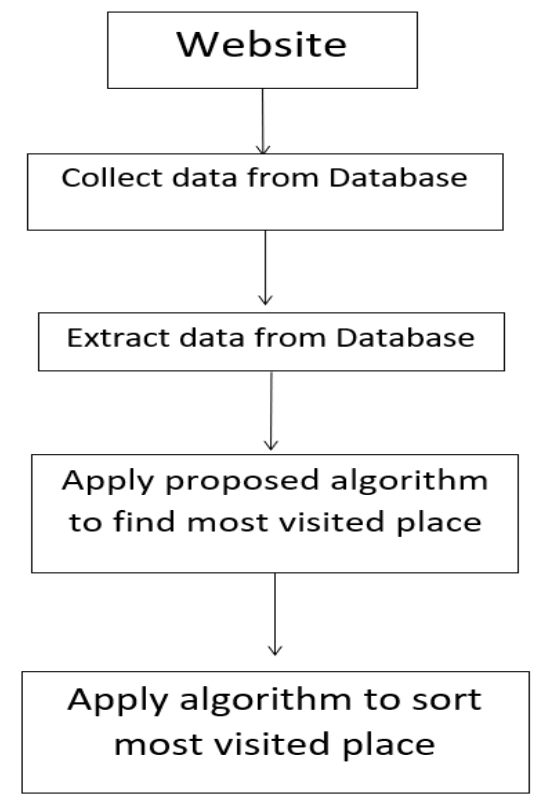

\section{EVALUATION}

The Linear Search algorithm starts searching from left side to right side or from any end and starts to search by comparing with each other. Here in this case the place which are being visited has the count on them as to how many travellers used our services already.

So by using Linear search algorithm we find the place which has been visited the most and also highlight it.

The pseudo code is as follows:

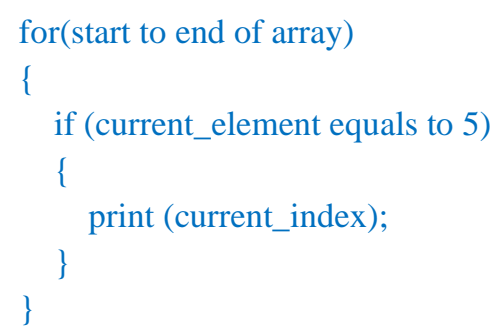

Next we use Quicksort Algorithm in order to sort the most visited places and $2^{\text {nd }}$ most, $3^{\text {rd }}$ most and so on. Thus, the travellers can choose any place they want to visit out of the visited places and can also get an opinion by seeing the reviews.

Pseudocode:

quickSort( arr[], low, high)

\{

if (low $<$ high)

\{

pi = partition(arr, low, high);

quickSort(arr, low, pi - 1);

quickSort(arr, pi + 1, high);

\}

\} 


\section{Intelligent Tourist Guide System using Web Development}

\section{RESULT}

While creating website or by implementing the paper to making the project, we need to focus on the frontend and backend of the website that we will create.

In the backend we write the code for creating the website. We use JavaScript to write the code and develop it accordingly. We create the database for storing the data of our travelling agents and also the traveller details and their interests. We create AWS database. We make login page for both travellers and agents. We also apply the algorithms here.

Now in the frontend both the agents and travellers can login and use the website.

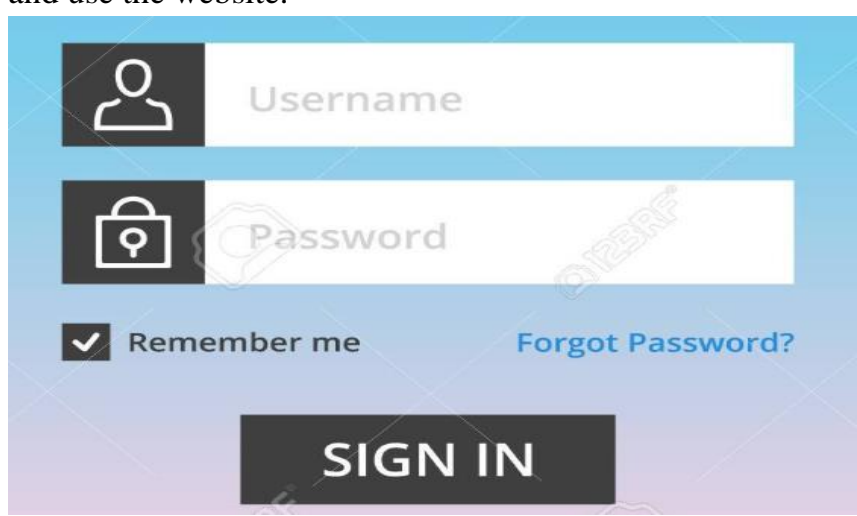

After logging in the website both parties can do their respective works.

\section{CONCLUSION}

This project is targeted mainly for the Tourism only. Its sole purpose is to make unknown places in the world famous and also help travellers to travel to different places which they never knew about. It also deals with algorithms which we use to find the most visited place and also to sort the places visited in descending order. We create website in which we keep the login option for both agents and travellers. Both can create account but agent can upload about their place and the traveller can only see the places and decide where they would travel. We also create database so that we can allow the agent to upload their data and store it in database.

\section{REFERENCES}

1. Muhammad Afzaal, Muhammad Usman, and Alvis Fong ,'Tourism Mobile App With Aspect-Based Sentiment Classification Framework for Tourist Reviews," in IEEE TRANSACTIONS ON CONSUMER ELECTRONICS, VOL. 65, NO. 2, MAY 2019, pp. 233-242. doi: 10.1109/TCE.2019.2908944

2. https://www.hackerearth.com/practice/algorithms/searching/linear-sear ch/tutorial/

3. https://www.interviewbit.com/tutorial/quicksort-algorithm/

\section{AUTHORS PROFILE}

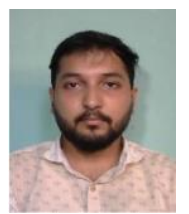

Abrar Islam,Student BTECH CSE (3 ${ }^{\text {rd }}$ year), SRM Institute of technology, Ramapuram abrar3islam@gmail.com

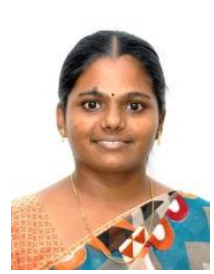

S.Priya M.E, Assistant professor CSE (O.G), SRM Institute of technology, Ramapuram pri1988cse@gmail.com

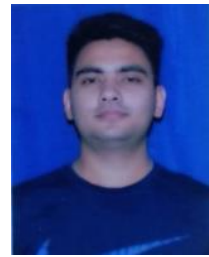

Aakrshan Sharma, Student BTECH CSE ( $3^{\text {rd }}$ year), SRM Institute of technology, Ramapuram aakrshansharma@gmail.com 